\title{
CONSELHO TUTELAR: CARACTERÍSTICAS, FUNÇÕES E ESTRUTURA DO ÓRGÃO
}

\author{
CHILD PROTECTION AGENCY: CHARACTERISTICS, FUNCTIONS AND STRUCTURE OF THE \\ BODY
}

\author{
Luiz Roberto Prandi ${ }^{1}$ \\ Pedro Henrique Marangoni ${ }^{2}$ \\ Lucas Marin Cebrian ${ }^{3}$ \\ Cleberson Silva Amaro Ramos ${ }^{4}$ \\ Elirani de Souza Chinaglia ${ }^{5}$
}

1Doutor em Ciências da Educação/UFPR. Mestre em Ciências da Educação Educação UNG/SP. Especialista em Educação Especial: Atendimento às Necessidades Especiais, Gestão Educacional, Educação do Campo, Gestão e Educação Ambiental, Metodologia do Ensino de Filosofia e Sociologia, Gestão de Projetos Sociais, Educação e Diversidade no Espaço escolar e Metodologia do Ensino Superior. Professor Titular e Pesquisador da Universidade Paranaense -UNIPAR.

${ }^{2}$ Bacharel em Direito pela Universidade Paranaense - UNIPAR - Umuarama - Paraná, Pós-Graduando em Docência do Ensino Superior, Pós-Graduando em Análise Criminal, Mestrando em Direito Processual e Cidadania - UNIPAR e Bolsista UNIPAR/CAPES.

${ }^{3}$ Bacharel em Direito pela Universidade Paranaense - UNIPAR - Umuarama - Paraná.

${ }^{4}$ Bacharelando em Direito pela Universidade Paranaense - UNIPAR - Umuarama - Paraná e participante do Programa de Iniciação Científica - PIC/UNIPAR.

${ }^{5}$ Bacharela em Direito/UNIPAR, especialista em Direito Civil e Processual Civil, especialista em Direito Previdenciário e professora da Universidade Paranaense - UNIPAR Umuarama - Paraná.

Recebido em julho de 2019 Aceito em julho de 2019
PRANDI, L. R.; MARANGONI, P. H.; CEBRIAN, L. M.; RAMOS, C. S. A.; CHINAGLIA, E. de S. Conselho tutelar: características, funções e estrutura do órgão. Akrópolis Umuarama, v. 27, n. 1, p. 93-100, jan./jun. 2019.

\section{DOI: 10.25110/akropolis.v27i1.7623}

Resumo: O presente artigo tem como escopo apresentar os aspectos gerais do Conselho Tutelar, de modo a verificar suas características, como permanência, autonomia e não jurisdição. Além de realizar um estudo pormenorizado das atribuições, por meio de seu atendimento, possibilidade de aplicação de determinas medidas e execução de suas decisões. Analisam-se quais tarefas fogem ou até mesmo extrapolam sua competência, fator que gera uma visão do Conselho Tutelar como um órgão de segurança pública, com atuação ostensiva, quando que, na verdade, trata-se de um órgão com atuação na seara administrativa. Ademais, tem por objetivo, verificar o funcionamento de suas estruturas, por meio de seus responsáveis, além da forma de atuação dos conselheiros, bem como, a remuneração destes e o orçamento do órgão. Desse modo, o respectivo estudo busca evidenciar quais são as reais atribuições e funções do Conselheiro Tutelar, por meio de pesquisa bibliográfica e legislativa e, ainda, traçar as diretrizes da estrutura do órgão. Por fim, fica evidenciado que o Município, como responsável pela criação e manutenção do Conselho Tutelar, deve dispor de meios de capacitação dos atuais e futuros Conselheiros para estes sejam preparados para desempenhar suas funções de acordo com o que a legislação determina.

Palavras-chave: ECA; Conselho; Conselheiro.

AbstRact: The purpose of this article is to present the general aspects of the Child Protection Agency (Conselho Tutelar - CT), in order to verify its characteristics, such as permanence, autonomy and non-jurisdiction. Moreover, it aims at conducting a detailed study of its attributions through its attendance, possibility of applying certain measures and enforcement of its decisions, analyzing which tasks are deviated or even beyond their competence, a factor that generates a view of the Child Protection Agency as a public security entity, with an ostensive performance, when, in fact, it is an entity that should operate within the administrative area. Furthermore, it aims at verifying the operation of its structures through their managers, in addition to the performance of the counselors, as well as their compensation and the CT budget. Thus, this article is focused on highlighting and studying the real duties and functions of the Counselors through a literature review and legislative research, tracing the guidelines of the entity's structure. Finally, 
it can be noted that the Municipality, responsible for the creation and maintenance of the Child Protection Agency, must have the means of training current and future Counselors in order to prepare them to perform their duties according to the law.

Keywords: Child and Adolescent Statute; Council; Counselor.

\section{INTRODUÇÃO}

O Conselho Tutelar, segundo dispõe sua definição legal, trata-se de um órgão permanente, autônomo e não jurisdicional, encarregado pela sociedade de zelar pelo cumprimento dos direitos das crianças e dos adolescentes.

A Lei n. ${ }^{\circ} 8.069$ de 13 de julho de 1990, conhecida como Estatuto da Criança e do Adolescente (ECA), não só criou o Conselho Tutelar como também positivou, compilou e, inclusive, sistematizou uma série de direitos das crianças e dos adolescentes.

$\mathrm{E}$, embora as atribuições do Conselho estejam previstas, de maneira expressa e clara, em um rol exemplificativo no artigo 136 do ECA, há, ainda, um pensamento distorcido e equivocado, por parte da sociedade, acerca das funções deste órgão.

Ocorre que, infelizmente, tal equívoco se estende até mesmo aos Conselheiros Tutelares, que, na maioria das vezes, não passam por uma capacitação antes de iniciarem suas atividades.

Assim, não é raro presenciar um ConseIheiro Tutelar realizando tarefas que fogem, ou até mesmo extrapolam, sua competência.

Atividades como interferir na dinâmica familiar; estipular alimentos em favor do adolescente; e retirar o menor de idade dos pais para entregá-lo a outro parente, sem que haja situação de risco, não são atribuições do Conselho.

Por isso, dente outros fatores, o ConseIho Tutelar ainda é visto, por grande parte da população, como um órgão de segurança pública, com atuação ostensiva, quando que, na verdade, trata-se de um órgão com atuação na seara administrativa.

Desse modo, o presente artigo é direcionado no sentido de evidenciar e estudar quais são as reais atribuições e funções do Conselheiro Tutelar, por meio de pesquisa bibliográfica e legislativa e, ainda, traçar as diretrizes da estrutura do órgão.

\section{CARACTERÍSTICAS DO CONSELHO TUTE- LAR}

Ao elaborar o texto legal, o legislador federal optou por incluir a definição de ConseIho Tutelar, redigindo-a no artigo 131 do ECA, da seguinte forma: "O Conselho Tutelar é órgão permanente e autônomo, não jurisdicional, encarregado pela sociedade de zelar pelo cumprimento dos direitos da criança e do adolescente, definidos nesta Lei." (BRASIL, 1990).

Analisando-se o supracitado artigo, é possível abstrair, no mínimo, três características do referido órgão, quais sejam: (i) permanência; (ii) autonomia; e (iii) não jurisdição.

Estudando-as, e, sem mesmo consultar o rol de atribuições do Conselho, é possível, por meio de um raciocínio lógico dedutivo, delinear os contornos e limites de suas funções.

\subsection{Permanência}

Menos expressiva, a permanência é a primeira característica a ser notada no dispositivo legal. Pode-se dizer que, dentre as três mencionadas, ela é a que possui o menor grau de importância, haja vista que diz pouco sobre o órgão. Além, é claro, de ser um ponto de controvérsias entre os autores.

Neste sentido, enquanto alguns autores a interpretam de maneira literal, defendendo que diz respeito a sua existência, outros autores sustentam que tal característica diz respeito, na verdade, a atuação do Conselho.

Assim, quanto a primeira corrente, o entendimento é que a permanência significa que o órgão, a priori, não pode ser extinto, restando, tão somente, a previsão legal quanto ao processo de eleição e substituição dos conselheiros, que ocorre a cada quatro anos.

Desse modo, o legislador: "[...] ao afirmar que o conselho tutelar é órgão permanente, quis atribuir-Ihe caráter perene, ou seja, quis estabelecer que uma vez criado, o órgão não pode ser extinto, sendo cabível, tão somente, a renovação de seus componentes após o exercício de mandato de três anos." (AMIM; SANTOS E MORAES, 2015, p. 490).

Por sua vez, aqueles que compreendem permanência sob a ótica da atuação do ConseIho, entendem que o legislador previu tal característica no intuito de atribuir caráter perene ao Conselho Tutelar, isto é, o órgão: "[...] desenvolve uma ação contínua e ininterrupta não podendo ser extinto, ignorado ou ter suas funções suspensas, uma vez que as ocorrências que en- 
volvem crianças e adolescentes na tem dia certo para se manifestar, e as soluções devem ser imediatas." (FONSECA, 2015, p. 255). De qualquer forma, observamos que ambas correntes, apesar de suas divergências, condizem com a impossibilidade jurídica de extinção do Conselho Tutelar.

\subsection{Autonomia}

A segunda característica prevista na Lei, bem como a segunda com maior grau de importância, trata-se daquela que atribui ao Conselho o caráter de autônomo.

Dentre as três características ora estudadas, a autonomia deve ser interpretada da maneira mais cautelosa possível, para evitar equívocos conceituais.

Neste sentido, como dispõe Kozen (2015), o legislador federal, quando atribuiu o caráter de autônomo ao Conselho, não definiu a natureza dessa autonomia e, tampouco, estabeleceu quais os seus limites.

Assim, segundo o autor, a temática trata-se de matéria concernente ao direito administrativo, que considera como autônomos aqueles órgão situados na cúpula da Administração, imediatamente abaixo dos órgãos independentes, com autonomia administrativa, financeira e técnica.

Todavia, a autonomia atribuída ao Conselho Tutelar trata-se, meramente, de autonomia funcional, a qual resulta na não subordinação do Conselho Tutelar a outro órgão do Poder Público.

Isto é, o Conselho Tutelar, diante da situação fática, decide, de maneira autônoma, acerca das medidas cabíveis. Sendo que suas decisões podem ser revistas, em ações próprias, apenas pelo Poder Judiciário, como dispõe o artigo 137 do ECA: "As decisões do Conselho Tutelar somente poderão ser revistas pela autoridade judiciária a pedido de quem tenha legítimo interesse." (BRASIL, 1990).

Neste sentido, conforme preceitua Liberati (2015, p. 167), o Conselho Tutelar é um órgão autônomo porque, ao decidir e aplicar as medidas protetivas, não necessita de ordem judicial, bem como exerce sua função com independência, mas sob a fiscalização do Conselho Municipal, da autoridade judiciária, do Ministério Público e de entidades civis que trabalham com a população infanto-juvenil.

Ainda, conforme o autor, o Conselho Tu- telar foi criado, justamente, para atuar de maneira autônoma e livre em relação à Administração Pública, delegando à lei municipal a conformação de sua existência, forma de atuação, processo de escolha, não permitindo influências e ingerências em sua atuação.

Assim, há de se ressaltar que: "A dita autonomia não impede, contudo, a vinculação - e não subordinação!- administrativa do conselho à Administração Pública, especialmente, para fins orçamentários, uma vez que é o Poder Executivo Municipal o responsável pela sua criação e manutenção." (AMIM; SANTOS E MORAES, 2015, p. 490).

Sendo assim, ainda que o legislador não tenha delimitado a definição de autonomia, bem como especificado sua extensão, por meio de uma interpretação sistemática dos dispositivos legais que dizem respeito ao Conselho, conclui-se, ante o exposto, que se trata de uma autonomia funcional.

\subsection{Não jurisdição}

Pode-se dizer que aqui resida, talvez, a característica mais importante atribuída pelo legislador federal ao Conselho Tutelar, pois, ao defini-lo como "não jurisdicional", o legislador situou o órgão na esfera administrativa. Assim, restou claro que o julgamento de conflitos de interesses não deve ser julgado pelo Conselheiro Tutelar, mas, sim, pelo Juiz da Vara da Infância e Juventude.

Portanto, ao Conselho Tutelar - como órgão cujos atos são de natureza administrativa não incumbe julgar casos, no sentido de dizer o direito no caso concreto ou, até mesmo, aplicar sanções de natureza judicial.

Assim, como se verá adiante, ao se deparar com casos cuja a perda ou suspensão do poder familiar é entendida como necessária, deve o Conselheiro Tutelar representar ao Ministério Público para que este, então, dentro de sua competência, tome as medidas cabíveis.

Conforme dispõe Amim, Santos e Moraes (2015, p. 491), não é raro presenciar conseIheiros tutelares interferindo na dinâmica familiar, estipulando alimentos em seu favor; estabelecendo normas de visitação ou, ainda, retirando a criança ou adolescente dos pais, afim de entregá-las a outro parente, mesmo que, nesta última situação, não haja situação de risco que justifique a adoção desta providência pelo Conselheiro. Tal forma de atuação, dependendo do 
caso concreto, pode causar a destituição do conselheiro, além, é claro, de sujeitá-la às penalidades cíveis ou penais.

O Conselheiro Tutelar deve estar atento para não realizar tarefas que fogem, ou, até mesmo, extrapolam sua competência, devendo ficar adstrito ao texto legal, respeitando o princípio da legalidade administrativa.

\section{ATRIBUIÇÕES}

As atribuições do Conselho Tutelar estão previstas em um rol exemplificativo no artigo 136 que, inclusive, foi elaborado de maneira assistêmica, pois trata de modo idêntico categorias de funções completamente diferentes. Enquanto algumas atribuições são condizentes com a realização das finalidades institucionais do ConseIho, outras são meramente instrumentais.

Neste sentido, a atribuição de requisitar serviços públicos e a de expedir notificações são exemplos de funções não condizentes com a finalidade do Conselho, pois apenas agem como instrumento para a realização de seus objetivos. (KOZEN, 2015, p. 8)

Assim, dispõe o artigo 136 do Estatuto da Criança do Adolescente:

Art. 136. São atribuições do Conselho Tutelar:

I - atender as crianças e adolescentes nas hipóteses previstas nos arts. $98 \mathrm{e}$ 105 , aplicando as medidas previstas no art. 101, I a VII; II - atender e aconseIhar os pais ou responsável, aplicando as medidas previstas no art. 129, I a VII; III - promover a execução de suas decisões, podendo para tanto: a) requisitar serviços públicos nas áreas de saúde, educação, serviço social, previdência, trabalho e segurança; b) representar junto à autoridade judiciária nos casos de descumprimento injustificado de suas deliberações. IV - encaminhar ao Ministério Público notícia de fato que constitua infração administrativa ou penal contra os direitos da criança ou adolescente; V - encaminhar à autoridade judiciária os casos de sua competência; VI - providenciar a medida estabelecida pela autoridade judiciária, dentre as previstas no art. 101 , de I a VI, para o adolescente autor de ato infracional; VII - expedir notificações; VIII - requisitar certidões de nascimento e de óbito de criança ou adolescente quando necessário; IX - assessorar o Poder Executivo local na elaboração da proposta orçamentária para planos e programas de atendimento dos direitos da criança e do adolescente; $\mathbf{X}$ - representar, em nome da pessoa e da família, contra a violação dos direitos previstos no art. 220, § $3^{\circ}$, inciso II, da Constituição Federal; XI - representar ao Ministério Público para efeito das ações de perda ou suspensão do poder familiar, após esgotadas as possibilidades de manutenção da criança ou do adolescente junto à família natural XII - promover e incentivar, na comunidade e nos grupos profissionais, ações de divulgação e treinamento para o reconhecimento de sintomas de maus-tratos em crianças e adolescentes. Parágrafo único: Se, no exercício de suas atribuições, o Conselho Tutelar entender necessário o afastamento do convívio familiar, comunicará incontinenti o fato ao Ministério Público, prestando-lhe informações sobre os motivos de tal entendimento e as providências tomadas para a orientação, o apoio e a promoção social da família. (BRASIL, 1990, s.p. ).

Como se observa no supracitado artigo, o Conselho Tutelar trata-se de um órgão incumbido de proteger os interesses da criança e do adolescente, podendo, para tanto, requisitar serviços na área da educação, da saúde, serviço social, trabalho, segurança e previdência. Sendo que, na maioria das vezes, o trabalho do ConseIheiro é mais requisitado quando é necessário fazer solicitação de vagas nas escolas públicas e visitas domiciliares no caso de abusos e maus-tratos.

Todavia, para fins metodológicos, as atribuições previstas no ECA podem ser dividas em: atender, aplicar medidas e executar suas decisões. Dessa forma que serão agora estudados.

\subsection{Atender}

Quando se fala em atendimento prestado pelo Conselho Tutelar, nota-se que há duas espécies contidas no artigo 136: atendimento direcionado as crianças e aos adolescentes (inciso I); e o atendimento aos pais ou responsáveis (inciso II).

O Estatuto, todavia, não prevê como ocorrerão tais atendimentos, necessitando, para tanto, que cada Município promova a elaboração 
de legislação municipal suplementar acerca da matéria.

E, como aduz Kozen (2015, p.8), o Conselho deve dispor de ferramentas como: a realização das diligências necessárias ao conhecimento pleno do caso, a busca de informações, a ouvida de pessoas in loco, a convocação dos envolvidos para serem ouvidos, a realização de diligências para estudos e pesquisas, assim como outras tantas formas de reunir elementos de convicção.

Por conseguinte, dispõe o artigo 136 do ECA: "São atribuições do Conselho Tutelar: I atender as crianças e adolescentes nas hipóteses previstas nos arts. 98 e 105, aplicando as medidas previstas no art. 101, I a V. II - atender e aconselhar os pais ou responsável, aplicando as medidas previstas no art. 129, I a VII;" (BRASIL, 1990).

O próximo tópico é direcionado, justamente, no estudo dessas medidas.

\subsection{Aplicar medidas}

Como mencionado anteriormente, o Conselho Tutelar deverá atender as crianças e os adolescentes quando ocorrer uma das hipóteses previstas nos artigos 98 e 95 do ECA. Tais dispositivos legais dizem respeitos às chamadas "medidas de proteção".

Vejamos, portanto, o conteúdo dos respectivos artigos:

\section{Art. 98. As medidas de proteção à crian- ça e ao adolescente são aplicáveis sem- pre que os direitos reconhecidos nesta Lei forem ameaçados ou violados: I - por ação ou omissão da sociedade ou do Estado; II - por falta, omissão ou abuso dos pais ou responsável; III - em razão de sua conduta. \\ Art. 105. Ao ato infracional praticado por criança corresponderão as medidas pre- vistas no art. 101.}

Isto é, ocorrendo ato infracional, ou violação aos direitos do menor por: ação ou omissão do Estado ou da sociedade; por falta, omissão ou abuso dos pais ou responsáveis; ou em razão de sua própria conduta, poderá o Conselho Tutelar aplicar as chamadas medidas de proteção, que estão dispostas da seguinte forma no artigo 101, I a V:

Art. 101. Verificada qualquer das hipóteses previstas no art. 98, a autoridade competente poderá determinar, dentre outras, as seguintes medidas: I - encaminhamento aos pais ou responsável, mediante termo de responsabilidade; II - orientação, apoio e acompanhamento temporários; III - matrícula e frequência obrigatórias em estabelecimento oficial de ensino fundamental; IV - inclusão em serviços e programas oficiais ou comunitários de proteção, apoio e promoção da família, da criança e do adolescente $\mathrm{V}$ - requisição de tratamento médico, psicológico ou psiquiátrico, em regime hospitalar ou ambulatorial; [...].

As respectivas medidas supracitadas, como o próprio texto legal determina, são aplicáveis aos menores. Contudo, quando diz respeito ao atendimento dos pais e responsáveis, previsto no artigo 136 do ECA, as medidas a serem aplicadas serão aquelas previstas no artigo 129 do mesmo diploma legal:

Art. 129. São medidas aplicáveis aos pais ou responsável: I - encaminhamento a serviços e programas oficiais ou comunitários de proteção, apoio e promoção da família; II - inclusão em programa oficial ou comunitário de auxílio, orientação e tratamento a alcoólatras e toxicômanos; III - encaminhamento a tratamento psicológico ou psiquiátrico; IV - encaminhamento a cursos ou programas de orientação; $V$ - obrigação de matricular o filho ou pupilo e acompanhar sua freqüência e aproveitamento escolar; VI - obrigação de encaminhar a criança ou adolescente a tratamento especializado; VII - advertência; [...].

Ressalta-se que o ato de aplicar medidas, tanto aos menores quanto aos pais ou responsáveis, trata-se de ato unilateral, haja vista que o Conselho não necessita obter, necessariamente, adesão do destinatário da medida. Sendo que, havendo discordância, o destinatário pode requerer a revisão judicial da medida aplicada, em ação própria, conforme dispõe o artigo 137 do estatuto da Criança e do Adolescente (KOZEN, 2015, p. 8). Com isso, verifica-se evidente o poder de atuação do Conselho Tutelar e sua autonomia, não havendo a necessidade de que a imposição da medida seja por intermédio do Poder Judiciário.

\subsection{Executar suas decisões}


Esta última espécie de atribuição possui estrita ligação com uma das características esboçadas no início do estudo, que se trata da autonomia do Conselho.

O artigo 137 do ECA estabelece: "As decisões do Conselho Tutelar somente poderão ser revistas pela autoridade a pedido de quem tenha legítimo interesse". (BRASIL, 1990).

Desse modo, o legislador não só outorgou autoridade administrativa ao Conselho para tomar providências diante do caso concreto, como também lhe atribuiu a capacidade de executar suas próprias decisões, evidenciando assim a sua autonomia funcional, que é, inclusive, necessária para efetividade da atividade do órgão.

\section{ESTRUTURAÇÃO DO CONSELHO TUTE- LAR}

\subsection{Disposições gerais}

A materialização do proposto pelo caput do art. 227 da Constituição Federal, no tocante à proteção prioritária da criança e do adolescente, concretizou-se na criação do Conselho Tutelar. Órgão, como já mencionado, de característica permanente, autônoma e não jurisdicional.

A Lei $n^{\circ}$. 8.069/90 ocupou-se de direcionar os responsáveis pela estruturação desse órgão, para que dispusesse a ele condições de manter suas características atuantes, evitando, deste modo, quaisquer interferências de cunho particularista ou sua inércia na proteção dos interesses infanto-juvenis.

Neste sentido, Tavares (2015, p. 492) expõe que: "É do município, por meio de lei de iniciativa do Poder Executivo, a competência para instituição do conselho tutelar, assim como para a determinação das normas de caráter especial atinentes ao órgão." O que se trata como lógico, pelo fato de a atuação do Conselho Tutelar ser envolta de interesse local.

O legislador incumbiu ao Município tal tarefa por ir ao encontro com a pretensão legal de assegurar a criança e ao adolescente proteção absoluta e prioritária, sendo, de maneira eficaz, alcançada quando da proximidade de atuação em relação a esse grupo vulnerável.

Porém, o texto legal foi cauteloso ao incumbir que o Município fosse responsável pela criação e disposição de recursos para a manutenção do órgão, vinculando a responsabilidade do Chefe do Poder Executivo Municipal pela sua não observância. Interpretação esta que resulta da análise do art. 132 e do parágrafo único do art. 134 do ECA.

Local, dia e horário de atendimento também são cruciais para alcance da integral proteção aos direitos da criança e do adolescente, já que a vulnerabilidade, em alguns casos, não é perceptível ou previsível.

\subsection{Atuação dos conselheiros}

A atuação dos conselheiros tutelares, como já dito nos tópicos anteriores, deve ser perene, sendo necessário, conforme anotação de Patrícia Silveira Tavares (2015, p.493), fixação, por meio de lei municipal, de atendimento em todos os dias da semana, inclusive fixando o sistema de plantões para finais de semana e feriados.

Importante é o apontamento feito por Fonseca (2015, p. 258) no sentido de que não pode haver o cerceamento das atividades do Conselho, sendo obrigatória a manutenção de suas atividades por no mínimo um membro plantonista, condição esta subtraída da característica de permanência do órgão.

A priorização desse atendimento não acontecerá se não for proporcionado a visibilidade desse órgão e a sua frequente exposição aos cidadãos que dele necessitam. Nisso, percebemos que além da fixação de atendimento em todos os dias da semana, o local de atendimento deve ser de conhecimento fácil da população, não podendo se reservar a locais distantes ou de difícil acesso ou dividir espaço em local que torne inviável o atendimento em dias de ausência de expediente das repartições publicas locais.

Ademais, outra questão que se busca evitar com a inclusão física do Conselho Tutelar em mesmo local de outras repartições públicas é a perda indireta de sua autonomia, já que em certos momentos deverá ir de encontro com interesses da administração pública local, o que será seriamente comprometido ante a proximidade física, que pode gerar comprometimento constante, criando no público local a ideia "[...] de que o Conselho tutelar fosse mais uma repartição da Prefeitura e, perigosamente, submissa aos mandos e desmandos do administrador de plantão." (LIBERATI, 2015, p. 167).

Ante o exposto, para que o Conselho possa alcançar o objetivo para o qual foi criado, bem como obter maior aproximação do público 
alvo, deverá, no imaginário das pessoas, ser desvinculado totalmente de influências das autoridades políticas locais.

\subsection{Orçamento do órgão e remuneração dos conselheiros}

$\mathrm{O}$ art. 134 do Estatuto da Criança e do Adolescente ainda versa sobre os recursos para funcionamento do Conselho Tutelar e para remuneração dos conselheiros, dispondo em seu parágrafo único que: "Constará da lei orçamentária municipal e da do Distrito Federal previsão dos recursos necessários ao funcionamento do Conselho Tutelar e à remuneração e formação continuada dos conselheiros tutelares" (BRASIL, 1990).

Nota-se que a legislação federal preocupou-se em dirimir quaisquer dúvidas quanto a fonte dos recursos para manutenção das atividades protetivas desenvolvidas pelo órgão, visando o resguardo da autonomia funcional do Conselho.

Contudo, é de extrema dificuldade firmar a autonomia funcional de um órgão se não estiver assegurada sua autonomia financeira, sendo possível investidas políticas, utilizando-se da diminuição ou esvaziamento do orçamento do órgão, no intuito de coibir as atividades do Conselho que são desagradáveis aos olhos do administrador público local ou de seu corpo político.

Do texto também se extrai que o legislador buscou resolver problemas correntes ou futuros quanto a remuneração dos conselheiros, dado que em alguns municípios a remuneração inexistia ou era ínfima para o trabalho realizado.

Encontra-se na doutrina disposição que entende que, pelo fato de ser o cargo de conseIheiro um cargo honorífico, de relevante valor social, ou seja, um múnus público, não é adequado a remuneração de tais agentes. Contudo, quando Nucci (2016, p. 500) faz essas ponderações, há desencontro com a tratativa da realidade.

Desse modo, a atuação do conselheiro para ser efetiva, exige dedicação e disposição de tempo, não podendo ser confundida com a atuação de um jurado no Tribunal do Júri, já que essa ação não o impede de realizar suas atividades laborais, pois tal tarefa é por breve tempo.

Ressalte-se, ainda, que não há desmerecimento quanto a atividade do conselheiro em relação a do jurado, pois ambas têm relevante valor de contribuição social, porém a diferenciação se tornou oportuna somente para frisar a ne- cessidade de remuneração daquele.

Apesar de ser contrário a remuneração do conselheiro, Nucci (2015, p.502) acerta quando credita que não deve ser dada proporção maior ao salário dos conselheiros - aumentos excessivos ou desproporcionais com realidade do Município, pois pode incidir no perigo de ao visar a garantia da realização efetiva do serviço incorrer no erro de criar um local de remuneração com pouco ou nenhum retorno.

Em ato contínuo, Rossato, Lépore e Cunha (2015, p.377) entendem ser assertiva a disposição do legislador em prever verbas próprias para membros do Conselho Tutelar, obrigando o Governo Municipal a dispor de recursos do orçamento para propiciar cursos de atualização e formação continuada, visando o aperfeiçoamento das atividades em benefício dos direitos dessa faixa etária em estudo.

Por fim, o art. 136, IX, da Lei em questão traz como atribuição do Conselho Tutelar o assessoramento ao Poder Executivo local na elaboração da proposta orçamentária e dos recursos para realização de atendimento aos infantes.

Inclusive, Fonseca (2015, p. 259) aponta que é plausível, caso o Conselho seja afastado da elaboração do orçamento, reclamação junto ao Ministério Público ou Poder Judiciário para sua inclusão nas discussões e consequentemente sua reavaliação.

$\mathrm{Da}$ análise do art. 132 da Lei $\mathrm{n}^{\circ}$. 8.069/1990 extraímos determinações do legislador aos Municípios que elidem justificativas correntes amparadas por juízos de conveniência e oportunidade da Administração Pública.

A Lei $n^{\circ}$. 12.696/2012 alterou a duração do mandato do conselheiro tutelar para 4 (quatro) anos em detrimento do período anterior, que era de 3 (três) anos, visando à unificação das eleições para composição do Conselho em todo o país.

O conselheiro somente poderá ser reconduzido uma vez a função, sendo inaceitável o entendimento de que, como suplente, tenha exercido mandato por breve espaço de tempo, seja permitida nova reeleição. Tal condição deve se manter inexorável no intuito de coibir manipulações diversas, sendo possibilitado somente que, conforme aludido por Fonseca (2015, p. 263), após dois períodos de atuação, havendo intervalo de mandato, seja facultado a pessoa concorrer novamente ao cargo. 
O número de integrantes do órgão reforça sua qualidade de órgão colegiado, que busca consenso ou pelo menos razoabilidade em suas decisões, para melhor servir aos interesses da criança e do adolescente.

O fato de a escolha desses conselheiros ser encargo da sociedade local é a valorização dada pelo legislador ante o potencial da sociedade de resolver seus próprios problemas.

\section{CONSIDERAÇÕES FINAIS}

A criação do Conselho Tutelar representa um grande avanço na tutela dos direitos das crianças e adolescentes.

É, portando, indiscutível a relevância que órgão possui, seja diante da violação de direitos pelos pais, pela sociedade ou, até mesmo, pelo próprio Estado.

Contudo, em que pese a notoriedade do órgão, o Conselho Tutelar é, na maioria das vezes, e por grande parte da população, visto e entendido de maneira equivocada.

Enquanto há uma visão distorcida do Conselho enquanto órgão ostensivo de segurança pública, ele é, na verdade, um órgão situado na seara administrativa desprovido de jurisdição, fato este que, de modo algum, reduz sua importância.

Assim, o Conselheiro Tutelar deve estar atento as suas atribuições que a lei lhe determina, evitando realizar tarefas que fogem ou, até mesmo, extrapolam sua competência.

Destarte, o Município, enquanto responsável pela criação e manutenção do Conselho Tutelar, deve dispor de meios de capacitação dos atuais e futuros Conselheiros para estes sejam preparados para desempenhar suas funções de acordo com o que a legislação determina.

\section{REFERÊNCIAS}

AMIN, R. A.; SANTOS; A. M. S.; MORAES, B. M. O conselho tutelar. In: MACIEL, K. R. F. L. A (coordenação). Curso de Direito da Criança e do Adolescente: aspectos teóricos e práticos. 8. ed. rev. e atual. São Paulo: Saraiva, 2015.

BRASIL. Lei n. 8.069 de 13 de Julho de 1990. Estatuto da Criança e do Adolescente. Brasília: Senado Federal, 1990.

FONSECA, A. C. L. Direitos da criança e do ado- lescente. 3 ed. São Paulo: Atlas, 2015.

KONZEN, A. A. Conselho tutelar, escola e família: parcerias em defesa do direito à educação. Disponível em: http://www.pmpf.rs.gov.br/ servicos/geral/files/portal/ct_familia_escola.pdf. Acesso em: 13 maio 2019.

LIBERATI, W. D. Comentários ao estatuto da criança e do adolescente. 12. ed. São Paulo: Malheiros, 2015.

NUCCI, G.S. Estatuto da Criança e do Adolescente Comentado. 2. ed. ver. atual. ampl. Rio de Janeiro: Forense, 2015.

TAVARES, P. S. Curso de direito da criança e do adolescente: aspectos teóricos e práticos. 8 . ed. São Paulo: Saraiva, 2015.

\section{CONSEJO TUTELAR: CARACTERÍSTICAS, FUNCIONES Y ESTRUCTURA DEL SECTOR}

Resumen: Este artículo ha tenido como objetivo presentar aspectos generales del Consejo Tutelar de modo a verificar sus características, como permanencia, autonomía y no jurisdicción. Además de realizar un estudio pormenorizado de las atribuciones, por medio de su atención, posibilidad de aplicación de determinadas medidas y ejecución de sus decisiones. Se analizan cuales tareas huyen o hasta mismo extrapolan su competencia, factor que genera una visión del Consejo Tutelar como un sector de seguridad pública, con actuación ostensiva, cuando que en verdad se trata de un sector con actuación en el área administrativa. Por otra parte, tiene por objetivo verificar el funcionamiento de sus estructuras, por medio de sus responsables, además de la forma de actuación de los consejeros, así como, la remuneración de estos y el presupuesto del organismo. Así, el respectivo estudio busca evidenciar cuales son las reales atribuciones y funciones del Consejero Tutelar, por medio de investigación bibliográfica y legislativa y, aún, trazar directrices de la estructura del sector. Por fin, se evidencia que el Municipio, como responsable por la creación y manutención del Consejo Tutelar, debe disponer de medios de capacitación de los actuales y futuros Consejeros para que sean preparados para desempeñar sus funciones de acuerdo con lo que determina la legislación.

Palabras clave: ECA; Consejo; Consejero. 